Pedro Edmundo Gómez, osb.

Monasterio de Nuestra Señora de la Paz

San Agustín, Córdoba, Argentina.

\title{
Algunas cuestiones epistemológicas a propósito de la teología monástica medieval en Jean Leclercq (1)
}

\author{
(Cincuenta años de la publicación de L’amour des lettres et le désir de Dieu)
}

El teólogo Hans Urs von Balthasar a propósito de los temas joánicos en la Regla de san Benito escribía:

“... me parece que una teología benedictina debería cavar en profundidad y llegar a las fuentes no solo literarias o patrísticas sino bíblicas que la alimentan. Debería eliminar todo aquello que en la tradición teológica y espiritual (¡no me refiero a la Regla!), anterior o posterior a Benito restringe o fija en cierto nivel histórico aquello que es intemporal, o mejor dicho, de todos los tiempos. En la tradición uno puede usar todo, pero sin detenerse en ninguna parte. Ni aun en la hermosa (tal vez demasiado hermosa) literatura del siglo doce. Pues hoy no se trata tanto del amor a la literatura y del deseo de Dios, como del amor de Cristo humillado hasta la cruz y de la obediencia a Dios..." (2).

Y hacerlo planteaba temas siempre actuales, problemáticos y relacionados entre sí: las fuentes, la tradición (3) y la teología monástica medieval.

Esta última expresión generalmente aceptada por los estudiosos (4) para designar la teología, o mejor, la explicación teológica de la Sagrada Escritura elaborada

(1) Este artículo viene a completar otro anterior "Algunas consideraciones sobre la Teología Monástica de los siglos XI y XII", en Res-Vista 2 (2000), pp. 13-32.

(2) Hans Urs von Balthasar, "Los temas joánicos en la Regla de san Benito y su actualidad" (traducción del P. Pedro Max Alexander, osb.), en Proyecto 30 (1998), p. 99.

(3) Un filósofo ha definido la tradición como el "arraigo o enraizamiento del devenir en el ser". Cfr. Evaristo Palomar Maldonado, Sobre la Tradición. Significado, naturaleza y concepto, Scire/ Balmes, Barcelona, 2001.

(4) Según Evangelista Vilanova, osb, fue en ocasión de un congreso en Dijon para recordar el IX centenario de la muerte de San Bernardo (1953) cuando recibió derecho de ciudadanía, las actas fueron publicadas con el título Saint Bernard théologien, en Analecta Sacri Ordinis Cisterciensis 9 (1953), III y IV. Allí hay un artículo de Jean Leclercq titulado justamente "S. Bernard et la théologie monastique du XII ${ }^{\mathrm{e}}$ siècle", pp. 7-23. 
en los monasterios medievales, es relativamente reciente, creada según Dom García M. Colombás, osb, por el dominico P. Duployé y popularizada desde el año 1946 (5) por las investigaciones de Jean Leclercq, osb, a quien parece aludir el teólogo suizo citando el título su obra más conocida al decir: “... hoy no se trata tanto del amor a la literatura y del deseo de Dios...".

El R. P. M-D Chenu, op. enseñaba que a los pensadores medievales les gustaba recurrir al método del "exponere reverenter", es decir interpretar sin prejuicios la doctrina del otro autor, comprenderle con simpatía, entrar en su perspectiva y solo después de este enfoque adecuado lo criticaban (6). Podían estar en desacuerdo con un pensador, ya sea este teólogo o filósofo, cristiano o pagano, pero el requisito previo, para que esto no fuera solo un desacuerdo verbal o una decisión arbitraria, era entender su pensamiento desde su propio punto de partida y específicas coordenadas metodológicas. Y una vez entendido ya no era necesario refutarlo. Porque era una y la misma cosa el entenderlo en su plenitud y el conocerlo en sus intrínsecas limitaciones, valoraban de este modo la parte de verdad que había descubierto y comunicado. Esto implicaba, por cierto, no tomar el propio pensamiento como criterio para juzgar la verdad o el error del otro.

En estas pocas páginas intentaremos plantear cuatro cuestiones epistemológicas a propósito de la teología monástica medieval: existencia y significado, distinción de la escolástica, noción de ciencia y crítica neoescolástica, exponiendo reverentemente lo que Leclercq (7), monje, historiador y teólogo, enseñó especialmente en L'amour des lettres et le désir de Dieu (8), que es a la vez el título y la conclusión (9) de un hermoso libro publicado hace ya cincuenta años.

Recordemos que se trata de una obra de iniciación, donde nuestro autor "recompone las líneas fundamentales de la espiritualidad monástica del siglo XII” (10), surgida de las lecciones dictadas en el Instituto de Estudios Monásticos del Pontificio Ateneo San Anselmo de la Confederación Benedictina en Roma, durante el

(5) Cfr., Jean Leclercq, Pierre le Vénérable, Saint-Wandrille, 1946, p. 366, y "Médiévisme et unionisme", en Irénikon 19 (1946), pp.12 -14.

(6) Cfr. Marie-Dominique Chenu, en Divus Thomas 28 (1925). El exponere reverenter era como delimitar el obstáculo que se quería saltar; Cfr. Pierre Michaud-Quantin, en Études du vocabulaire philosophique du moyen âge.

(7) Nacido en Avesnes al norte de Francia (1911), ingresó en el monasterio luxemburgués de Clervaux (1928) y cursó estudios de eclesiología e historia en Roma y París, murió en 1993.

(8) L'amour des lettres et le désir de Dieu, Initiation aux auteurs monastiques du Moyen Age, Les Éditions du Cerf, Paris, 1957. Traducciones en italiano: Cultura umanistica e desiderio di Dio. Studio sulla letteratura monastica del Medio Evo, Firenze 1965, 1983, 1988; en alemán: Wissenschaft und Gottverlangen. Zur Mönchstheologie des Mittelalters. Düsseldorf 1963; en inglés: The Love of Learning and the Desire for God, New Cork, 1961, .. 1982; y en español: Cultura y vida cristiana, Iniciación a los autores monásticos medievales, Sígueme, Salamanca, 1965. Nuestras citas y notas están tomadas de la edición española, en caso contrario lo indicamos específicamente.

(9) Cultura y vida cristiana, op. cit., p. 301. En otra obra lo reafirma diciendo: “...los monjes de la edad media apenas podían imaginarse que uno pudiera hacerse un santo sin ser un hombre culto, formado en las bellas letras, que dan el gusto por todo lo que es elevado, y que son tan útiles para comprender las letras sagradas" (Témoins de la spiritualité occidentale, Cerf, Paris, 1965; Espiritualidad occidental. Testigos, Sígueme, Salamanca, 1967, p. 26).

(10) Carlos A. Disandro, El latín mystico, Siglo XII, San Bernardo de Clairvaux, Hostería Volante, La Plata, 1990, p. 10. 
invierno de 1955-1956, y en el contexto de la investigación teológica de la segunda posguerra, en que nacieron también la "nueva teología" francesa, la "teología de las realidades terrestres" y la "teología del judeocristianismo". Todas ellas comparten la idea de una teología vital y nutrida en la historia, "a fin de saber qué preguntas se deben plantear al pasado; y al hombre y al mundo de antaño a fin de reconocer su respuesta real constructiva y concreta para nuestra época" (11).

\section{CUESTIÓN I: LA EXISTENCIA Y EL SIGNIFICADO DE LA TEOLOGÍA MONÁSTICA MEDIEVAL}

En el siglo XII aparecen en el horizonte eclesial los "mendicantes" que buscaban una vida cristiana más auténtica y radical, evangélica pero no monástica, y que mostraban dos características: una en continuidad con la tradición, la frecuentación personal y comunitaria de la Palabra de Dios; y otra en ruptura, la sintonía profunda con las aspiraciones de una nueva sociedad naciente (12). De esta conjunción surgen nuevos modos de predicación popular, controversia con la heterodoxia y producción-comunicación teológica: germina la llamada primera escolástica. En ella la enseñanza universitaria incorporará, a la lectura litúrgica y espiritual de la Biblia, la dialéctica, es decir, el rigor intelectual, con su precisión conceptual y solidez argumentativa (13).

Es notable así el contraste entre dos teologías: monástica y escolástica, dos formas de pensar la fe que, aun no siendo antagónicas, tampoco se sitúan en estricta continuidad una de otra. Los elementos que caracterizan a la monástica explican las fuertes tensiones que surgieron entre su manera de entender la teología y el nuevo planteamiento que se afirmaba con la escolástica, a la que se acusó de querer reducir a categorías humanas de tipo racional lo que no procedía del hombre, sino que tenía su última y verdadera comprensión solo en el corazón. El problema de la escuela, como afirmaba una reconocida medievalista, "será el del certificare fidem, los monjes parecen comprometidos en clarificare fidem" (14).

Estos dos estilos o modelos teológicos brotaban y se injertaban en dos espiritualidades también distintas. Una era la de los monjes, que vivían en una fuerte

(11) Ted M. Schoof, La nueva teología católica, Ediciones Carlos Lohlé, Buenos Aires, 1971, p. 129.

(12) “... el burgués, como así se denomina al que vive en esos burgos, le escamoteará a los monjes algunas cosas para poder también él llegar a esa perfección. Una de las cosas de las que se apropia es la "lectura orante" o, como la llamaban los monjes, lectio divina (literalmente: lectura de las cosas divinas). Los monjes lo viven como una lectura individual, en el silencio del claustro o de la celda, y formaba parte de su oración contemplativa y solitaria. El laico, ciudadano, la vive en cambio en pequeños grupos de hermanos y hermanas, que se encontraban para escuchar a alguno de ellos que les leía en su lengua la Palabra y compartían después lo que le decía la Palabra a cada uno, y luego oraban juntos. Así, lentamente van surgiendo nuevos grupos de vida cristiana más auténtica, no monástica, que poco más tarde serán llamados "mendicantes". Así son los dominicos, los menores, los carmelitas, los siervos de María, los agustinos, los penitentes de Jesucristo y otros más" (Pedro Suárez, "El Rosario o Corona de Rosas ofrecida a María", en Anatéllei VII, 13 [2005], pp. 44-45).

(13) Cfr. Marie-Dominique Chenu, La théologie au douziéme siècle, Paris, 1966, p. 344.

(14) Mariateresa Fumagalli Beonio Brocchieri, El intelectual entre Edad Media y Renacimiento, Oficina de Publicaciones del CBC, UBA, Buenos Aires, 1997, p. 22. 
atmósfera escatológica (15) y en el despliegue a la vez "esplendoroso" y "simple" de la liturgia (16). Y otra, la de estos nuevos movimientos que enraizados en los vaivenes del mundo intentaban descubrir en la profanidad de sus estructuras e inquietudes un nuevo terreno donde se encarne la salvación y a la vez trataban de responder a las nuevas demandas, pero manteniendo, al menos en algunos casos, la dimensión sapiencial esencial a la teología cristiana (17).

La oposición entre estas dos teologías se verá agravada más tarde, en los siglos XVI-XVII (18) por el auge de la teología tridentina, positivo-escolástica o segunda escolástica, con su "esencialismo sistemático", que siendo más formal, centrada en las definiciones y en las estructuras axiomáticas deductivas claramente expresadas que la primera, consideraba a la monástica en una posición de menor estima, a lo sumo con un "papel oscuro de intermediarios" (Juan de Santo Tomás). Sin embargo, continúa toda una literatura teológico-espiritual a menudo muy abundante, como es el caso de Dionisio de Ryckel, quien mantiene la fidelidad a la tradición, si bien con escasa originalidad, excluyendo el así llamado divorcio entre teología y mística (19), que coexisten en el Cartujano fundiéndose y compenetrándose mutuamente (20).

Fueron necesarios varios siglos, precisamente hasta casi la mitad del siglo XX, para llegar a una neta individuación en el ámbito histórico-doctrinal de la existencia y significado de la teología monástica (21), y esta fue justamente la tarea realizada por Leclercq. El P. Chenu, su amigo y colega, lo dice de la siguiente manera:

"Hemos ponderado bastante la teología como ciencia y juntamente con ella, su instrumentación escolástica para poder situar ahora en el sitio que le corresponde y en su permanente valor, a la teología monástica. Entre los muchos beneficios que se deben a los trabajos de Dom Leclercq, no será el menor el que haya sacado del terreno acotado de la erudición al capital monástico, y de haber proclamado su consistencia permanente" (22).

(15) Por eso nuestro autor "no se cansaba de repetir que las grandes empresas misioneras de la Europa medieval y el influjo cultural de los cenobios eran resultado accidental de un ideal de acelerar, con la oración y el deseo, la venida del reino de Dios" (Bernabé Dalmau, Léxico de espiritualidad benedictina, Monte Casino, Zamora, 1995, p. 176).

(16) Cfr. Espiritualidad occidental. Testigos, op. cit., pp. 152ss.

(17) Cfr. Marie-Dominique Chenu, La théologie au douziéme siècle, op.cit., p. 150.

(18) Cfr. Gregorio Penco, "La herencia del monacato medieval", en CuadMon 157 (2006), pp. 140141.

(19) Cfr. Ignacio Andereggen, Contemplación filosófica y contemplación mística, Desde las grandes autoridades del siglo XIII a Dionisio Cartujano (S.XV), EDUCA, Buenos Aires, 2002.

(20) Cfr. Anselme Stoelen, "Denys le Chartreux", en Dictionnaire de Spiritualité III, Beauchesne, Paris, 1957, p. 448.

(21) Cfr. Ferruccio Gastaldelli, "Teologia monastica, teologia scolastica e lectio divina", en Analecta Cisterciensia 46 (1990), pp. 25-63.

(22) Marie-Dominique Chenu, ¿Es ciencia la teología?, Editorial Casal I Vall, Andorra, 1959, p. 126. El dominico también afirma la distinción: "La teología escolástica se presenta primeramente como un lenguaje, el lenguaje erudito y técnico, frente a una teología patrística y monástica que, a causa de su imprecisión, no podemos despreciar" (Idem., p. 64). La teología monástica, "según una denominación hoy en día muy en boga" y la escolástica son pues "dos formas de pensamiento" que se han desarrollado sucesivamente en teología. "Llámese justamente monástica a una de estas teologías porque sus maestros fueron generalmente monjes, porque, calando más adentro, 
El monje de Clervaux para afirmar la identidad de la teología monástica medieval profundizó la distinción, remarcando las diferencias, aunque a veces parece estar hablando de una verdadera "disyuntiva", conjeturamos que se trata de una "disyunción inclusiva", con la escolástica, sin hacer una caricatura de la misma sino basándose en una preferencia de lo experiencial, cultural y vital sobre la objetividad, universalidad y cientificidad del conocimiento, de la sapientia sobre la scientia, de la "ciencia del corazón" sobre la "ciencia del intelecto" (23). Según Dom Gregorio Penco, osb:

"Esto explica por qué la Edad Media estudiada por Dom Leclercq es la Edad Media monástica y no la Escolástica, aunque en los primeros años él incluyera en su investigación a un autor escolástico (Juan de París). Fue precisamente la distinción con el mundo de la Escolástica lo que confirió una unidad ideal al mundo espiritual de los monjes, la participación en un espíritu sapiencial común, la orientación de toda su existencia en un sentido contemplativo" (24).

Esta distinción que justifica hablar de "dos edades medias" (25): una monástica y otra escolástica, es ahora admitida de manera casi generalizada por los sociólogos e historiadores de las culturas y mentalidades, y hasta los mismos "hombres de la Edad Media tuvieron conciencia de ella" (26). A propósito de san Bernardo escribía:

"Es indudable que la diferencia entre la "edad media monástica" y la "edad media escolástica" no es una separación. Una y otra se influenciaron recíprocamente, y algunos monjes estuvieron más o menos comprometidos en el movimiento de la teología escolástica. Pero si se consideran por una parte los escritos escolares en su conjunto, y por otra los textos monásticos, es evidente que ambos crean dos atmósferas diferentes" (27).

esta teología está ligada a una determinada vivencia del mundo y de la economía cristiana en el mundo. Pero tiene un alcance que sobrepasa en mucho una mera coyuntura histórica y un éxito ocasional que perdería actualidad por el hecho de la evolución de la Iglesia..." (Idem., p. 126). Y agrega: "Esta teología monástica no es de ninguna manera un valor atrasado, desclasificado, como nos induciría a pensarlo un evolucionismo radical, por el que algunos se deslizan... Expresa -al igual que el Ordo monasticus mismo- unos valores de Iglesia y de humanidad, permanentes" (Idem., p. 127).

(23) Ermenegildo Bertola, "Teologia monastica e teologia scolastica", en Lateranum 34, (1968), pp. 237-271.

(24) Gregorio Penco, "Jean Leclercq y el concepto de tradición monástica", en CuadMon 141 (2002), p. 190.

(25) Jean Leclercq, "Mediévisme et unionisme", op. cit.

(26) Jean Leclercq, "Teología y oración”, en San Anselmo 15 (1985), p. 75. Como ejemplo cita en otro texto un fragmento de Gerhoh de Reichersberg donde critica a "unos lectores embriagados, saciados más del vino escolástico que del vino teológico" (Epist. at Hartmannum Brixin, PL 194, 1074, en Espiritualidad occidental. Testigos, p. 233).

(27) Espiritualidad occidental. Testigos, p. 328. 
Y precisa: "la existencia de dos formas diferentes de Teología no obliga desacreditar a una u otra, ni a juzgar a una en relación con la otra. Hay que aceptarlas como realidades que han respondido a las necesidades de la vida de la Iglesia" (28). Pero a nadie escapará que nuestro autor contrapone la teología monástica a la hegemonía escolástico tomista, o mejor dicho neoescolástica, en cuanto plus que completa a la teología especulativa analítica, siendo un modo distinto, legítimo y superior de acercarse a Dios, un camino heredado de los Padres de la Iglesia. Y se pregunta: “ ¿...cuál es la especial tarea de la teología monástica sino la de ocuparse en detectar, a lo largo de los tiempos y culturas, una línea no interrumpida a través de dos épocas como la patrística y la medieval?" (29). Sus numerosísimas publicaciones, mediante una continua y abundante referencia a las fuentes y a la tradición, son la respuesta misma a su pregunta. Esto ocurre especialmente como veremos en L'amour des lettres et le désir de Dieu.

\section{CUESTIÓN II. LA DISTINCIÓN ENTRE MONÁSTICA Y ESCOLÁSTICA EN L'AMOUR DES LETTRES ET LE DÉSIR DE DIEU}

El postulado de la distinción está presente ya en la Introducción donde leemos: "Notemos bien que los medios monástico y escolástico no están habitualmente en oposición, presentan un abierto contraste, pero están en relación uno con otro -se deben mucho uno a otro-" (30), y pasa a demostrarlo con ejemplos, compara dos textos, dos prólogos: el de Pedro Lombardo a su Comentario a las Epístolas de San Pablo y el de san Bernardo de Claraval a los Sermones super Cantica.

Y en el Apéndice III titulado La "Théologie spéculative" de Dom Bertrand (31) lo hace mostrando la alternativa entre la teología admirativa y especulativa:

"La teología monástica es una teología admirativa, y por eso supera a la teología especulativa. Admiración y especulación, dos palabras que designan una mirada. Pero la mirada de la admiración añade algo a la de la especulación. No ve necesariamente más, pero lo poco que entrevé, basta para poner al ser entero del contemplativo en estado de gozo y de acción de gracias" (32).

Si bien la disyuntiva, como una de sus ideas-eje, transita todo el libro, formación (primera parte) y fuentes (segunda parte), se hace totalmente notoria en la tercera donde aborda los frutos de la cultura monástica: obra literaria, teológica y el aporte a la liturgia.

(28) “Teología y oración”, op. cit., Idem., p. 76.

(29) Gregorio Penco, "Jean Leclercq y el concepto de tradición monástica", op.cit., p. 186.

(30) Cultura y vida cristiana, p. 13.

(31) p. 252 de la edición francesa.

(32) p. 277. 
Las comprobaciones que realiza son las siguientes:

a) Los géneros literarios (33) son de índole retórica, simple, y no dialéctico (34); edificante (35), glorificante (36) y pastoral (37). Los monjes prefieren la escritura a la palabra (38), afirmando así el primado de la experiencia, que es principio y fin de la teología monástica, sobre la especulación.

b) Una teología monástica (39) de carácter tradicional (40) con desconfianza de las novedades y vocabulario místico (41), lleno de imágenes (42), tendiente a evitar las controversias y los problemas inútiles (43); simple (44), piadosa y contemplativa (45); afectuosa (46), basada en la experiencia (47), testificada por la conciencia (48) y sabrosa en el orden de la gracia (49).

c) El poema de la liturgia (50) en la cual intervienen la literatura (51), la poesía (52), la música (53) y el arte (54), como sus elementos constitutivos y de los cuales la misma liturgia es su coronación (55). El contacto asiduo con las fuentes y la tradición, en la liturgia y en la lectio, hizo que evitaran los términos abstractos y se sirvieran de imágenes, símbolos y comparaciones que dan a sus obras una gran belleza literaria y poética.

En muchos lugares de la obra de 1957, contemporánea del bellísimo estudio de Chenu sobre la teología del siglo XII que es su natural y obligado complemento (56), encontramos presente la distinción y en otros recalca de manera sugestiva, a modo de argumento, el carácter de experiencia espiritual que existe en el monasterio (57). Pero este segundo elemento adquiere su plena significación en los textos en que la diferencia es evidente. Por ejemplo al hablar de las dos fuentes del pensamiento de san Gregorio Magno: su lectura, de carácter objetivo, y su experiencia,

(33) Cap. 8 .

(34) p. 215.

(35) p. 194.

(36) p. 199.

(37) p. 206.

(38) p. 189.

(39) Cap. 9.

(40) p.231.

(41) p. 240.

(42) p. 243.

(43) p. 251.

(44) Ibidem.

(45) p. 258.

(46) p. 261.

(47) p. 270.

(48) p. 273.

(49) p. 279.

(50) Cap. 10.

(51) pp. 283-285.

(52) pp. $285 \mathrm{ss}$.

(53) pp. 287 ss.

(54) p. 290.

(55) p. 301.

(56) Cfr. L'amour des lettres et le désir de Dieu, Avant-propos au $3^{a}$ édition. Cerf, Paris, 1990.

(57) p. 71. 
elemento subjetivo (58). También se puede apreciar en la divergencia entre disputatio y lectio (59), por la orientación de ambas: la primera se dirige a la inteligencia mientras que la segunda a todo el ser (60). En un lugar clave afirma:

"A diferencia de los escolásticos, cuyo interés se dirige a la quaestio, a la disputatio, y a la lectio concebida como una ocasión de presentar quaestiones, a los monjes les gustan los escritos en los que se trate de hechos y de experiencias más bien que de ideas, y que en lugar de ser la enseñanza de un maestro a un público universal y anónimo, estén dirigidos a un destinatario concreto, a un público determinado y conocido por el autor" (61).

Y en otro libro posterior subrayará claramente la diferencia metodológica entre ambas:

"A los procedimientos que las escuelas aplicaban a la pagina sacra -la disputatio, la quaestio- de la que saldrán las summae sententiarum, ellos prefieren la lectio divina y, cuando escribían, el "florilegio", destinado, no a la investigación intelectual, sino a la oración y a la meditación: oratio meditativa" (62).

En los claustros se hacía una teología distinta en función de la experiencia monástica, una fe vivida en un contexto particular el claustral en el cual se hermanaban y compenetraban el pensamiento religioso y la experiencia espiritual, la investigación intelectual de la verdad y el esfuerzo ascético por la perfección moral (63), "temperamentum scientiae et temperamentum cordis" (64). Razón por la cual entre sus elementos constitutivos tenían gran importancia la oración y la contemplación (65).

El parágrafo "La escuela y el claustro: sus relaciones y sus contrastes" (66) distingue la cultura gratuita, desinteresada y litúrgica, de tendencia "contemplativa" del monje, en la que predominaba la gramática y la retórica, orientada a vivir la fe, favorecer la oración y el crecimiento espiritual en una continua tensión escatológica

(58) pp. 40-42.

(59) p. 93.

(60) p. 109.

(61) pp. 187-188

(62) Espiritualidad occidental. Testigos, p. 326.

(63) Evangelista Vilanova, Historia de la Teología Cristiana I, Herder, Barcelona, 1987, p. 373.

(64) Carlos A. Disandro, op.cit., p. 7.

(65) San Bernardo decía: "se investiga de manera más digna, se halla más fácilmente la verdad, por la oración que por la disputa" (De consideratione V, 32), porque extremadamente respetuosos de las sagradas materias los monjes se oponían a las disputas que tanto apasionaban a los dialécticos. Pero esto tiene otra explicación, acaso más importante: el abuso de la dialéctica engendra una forma de curiosidad que rechazan en nombre de la humildad y simplicidad. Esta, según Pedro el Venerable, dirige la inteligencia a un solo objeto: buscar a Dios, no a discutir sobre Él. Si se busca de verdad a Dios se evitarán las discusiones demasiado sutiles y el fragor de las controversias que hacen perder la compunción y la paz del corazón. Y Pedro Comestor subraya nuevamente la distinción: "Los hay que se dan a la oración más que a la lectura: son los que habitan los claustros; hay otros que se dedican a la lectura y oran raramente: son los escolásticos" (Sermo 9: PL 198, 1747).

(66) Cultura y vida cristiana, pp. 234-239. 
bajo la mirada de Dios; y la preparación especializada para la "vida activa", la actividad pastoral, especulativa y polémica del clérigo, que debía responder a las cuestiones de orden intelectual o moral con el uso del lenguaje abstracto, claro y preciso de la dialéctica. Mostrando así un hecho indiscutible, la existencia, o mejor dicho la coexistencia de dos teologías, de dos edades medias. La diferencia entre ambos medios no estuvo nunca en las doctrinas, sino en el modo de pensar. Ciertamente hubo discrepancias como también las había habido entre unos Padres y otros, pero la razón siempre estuvo al servicio de la fe (67).

Los monjes, por ejemplo, al tratar del Santísimo Sacramento del Altar: "no veían jamás en él una ocasión de agitar problemas abstractos, sino que hablaban de él como de una realidad viva, que la Iglesia, en su liturgia, propone todos los días a su adoración con palabras bíblicas” (68). Por lo que concluye: “...toda la diferencia entre la teología escolástica y la de los monasterios procede de que una misma reflexión religiosa fue practicada en dos lugares y en dos medios distintos" (69).

La clave de este pluralismo teológico está en el contexto y la cultura, o mejor dicho, en la vida que se desenvuelve en diversos contextos y culturas, y en sus relaciones circulares con la fe cristiana que es la que engendra la multiplicad de teologías en la Iglesia. El movimiento sale de la fe vivida a la teología y retorna a ella (70). Nuestro autor parte de la idea de que a medios ambientes distintos respondieron experiencias heterogéneas con diferentes mentalidades y por consiguiente con diversos modos de reflexión religiosa. En su libro Consideraciones monásticas sobre Cristo en la Edad Media también leemos:

“... es normal que en medios de vida con diferente orientación aparezcan modos diferentes de reflexionar sobre la fe. La sociología de las teologías del siglo XII ilumina las características de cada una de ellas, las estructuras mentales de las que dependen y los medios de expresión que emplean” (71).

Este hecho de sociología histórica se reflejó también en un dato de historia del vocabulario (72), porque "la palabra teología, como todas las demás tiene, tiene una historia" (73):

(67) Pedro Abelardo y San Bernardo de Claraval, por citar solo a dos representantes, coincidían en el rechazo del racionalismo, la diferencia estuvo más bien en la actitud y en los objetivos que se planteaba cada uno. El maestro Pedro Abelardo, como muchos de sus contemporáneos, quería llevar lo más lejos posible la elaboración especulativa de los datos de la fe. Al aumentar el instrumental lógico-filosófico la razón espoleaba hacia una mayor profundización y comprensión de la realidad. Para el monje Bernardo, como también para muchos otros autores de su época, un pensar racional sobre Dios entendido como un estudio desencarnado no tenía sentido.

(68) p. 298.

(69) p.304.

(70) El título de la edición española de L'amour des lettres et le désir de Dieu que es Cultura y vida cristiana si bien no traduce literalmente el título original sí es una muy buena clave hermenéutica para su lectura.

(71) Jean Leclercq, Regards monastiques sur le Christ au Moyen-Age, Group Mame, Paris, 1993; Consideraciones monásticas sobre Cristo en la Edad Media, Descleé de Brouwer, Bilbao, 1999, p. 167.

(72) Evangelista Vilanova, Para comprender la Teología, Verbo Divino, Navarra, 1992, pp. 42-43. Cfr. Jean Leclercq, Études sur le vocabulaire monastique du moyen- âge, Roma, 1961, pp. 70-79.

(73) Espiritualidad occidental. Testigos, p. 325. 
a) A la aparición y desarrollo en la edad media de un tipo de reflexión influido primero por los métodos escolares, el Sic et non de Pedro Abelardo (74) y Guillermo de Auxerre, y luego por la utilización de los recuperados I y II Analíticos, Tópicos y Razonamientos sofísticos de Aristóteles, que condujeron a las quaestiones y estas a la disputationes, corresponde el uso del término teología en un sentido nuevo que designaba una actividad que era de orden científico, la "teología como ciencia", entendida esta como cognitio certa ex causis (75). Teología pensada y disputada.

b) A la persistencia y desarrollo de una reflexión religiosa de tipo tradicional, cuya fuente de inspiración era la misma existencia de los teólogos, tan profundamente marcada por la lectio divina y la liturgia, que se expresaba con un lenguaje que reserva gran espacio al simbolismo, la imaginación, la estética y la poesía (76), respondió la persistencia del sentido antiguo del término teología, es decir "teología como sabiduría", designando a la vez una forma de reflexión-expresión acerca del misterio de Dios y de oración a base de ascesis que termina en la contemplación, es decir, un modo sapiencial de conocimiento alimentado por la oración, que lo prepara y del cual resulta (77). Teología rezada y contemplada.

Con razón afirmaba Étienne Gilson, uno de los maestros de Leclercq, que "el encuentro de la fe cristiana con el platonismo de los mitos y los misterios fue el encuentro de dos pensamientos religiosos, mientras que el encuentro con el aristotelismo fue el encuentro de una religión en cuanto tal con una filosofía en cuanto tal" (78). Tratando el tema de la asunción del instrumental aristotélico Bruno Forte señala que:

“... puede hablarse de tres sucesivas entradas de Aristóteles en el mundo teológico cristiano, respectivamente como maestro de gramática..., de razonamiento (siglo XII: asunción de la dialéctica) y de conocimiento del hombre y del mundo (comienzos del siglo XIII)... los diferentes aspectos que de él se fueron conociendo sucesivamente determinarán... diversos regímenes metodológicos" (79).

(74) "Antes de él no consistirá en desprender del dato revelado unas consecuencias nuevas, unas "conclusiones teológicas" sino más bien consistía en un inventario de la revelación. La escolástica será una "investigación"; su santo y seña será: Quaeritur y Solet quaeri. La patrística es una posesión, una confessio fidei" (Idem.).

(75) Evangelista Vilanova, Para comprender la Teología, op. cit., p. 41.

(76) Consideraciones monásticas sobre Cristo en la Edad Media, op . cit., pp. 168-169.

(77) “... es un "conocimiento superior” que es recibido de Dios y cuya expresión se dirige a Dios mismo: el entusiasmo provocado en el alma por la revelación se hace alabanza, himno, acción de gracias; se expansiona en oración" (Espiritualidad occidental. Testigos, p. 325).

(78) Etienne Gilson, "Le christianisme et la tradition philosophique", en Revue des Sciences Philosophiques et Théologiques 30 (1941-1942), pp. 249-266.

(79) Bruno Forte, La teología como compañía, memoria y profecía, Introducción al sentido y al método de la teología como historia, Sígueme, Salamanca, 1990, p. 104. Conviene precisar un poco más el proceso. En la primera etapa ingresa la Logica vetus que llegó a través de Boecio y aportó una clasificación de nociones y un análisis de proposiciones, proporcionando los instrumentos racionales necesarios para el análisis textual. La Alta Edad Media concibió la Sacra Pagina como un conocimiento del texto bíblico fundamentado en la Gramática. En la segunda etapa llega la Logica nova, el resto del Organon aristotélico, trayendo una teoría científica del 
En la segunda fase, la dialéctica es una expresión refleja de la nueva vivencia individual y social, revela el espíritu de la época y denuncia la transformación que se estaba realizando con respecto al pasado. La teología monástica se destacaba por el uso de las auctoritates, este método fue también utilizado por los escolásticos, pero en ellos aparecen características intelectuales que son propias de su momento histórico-cultural, "veritas, filia temporis" (Bernardo de Chartres), utilizaban las autoridades, con respeto pero sin servilismo, para ir más lejos, como, según decía el historiador Jacques Le Goff, los marinos usan del mar.

Hablando de la theologia-sapientia en su artículo "Teología y oración” Leclercq añade:

"La noción de Teología era una palabra de Dios no analizada intelectualmente, discutida en la escuela, sino contemplada, amada, adorada, proclamada en la alabanza y la acción de gracias. Sin duda implica una parte de conocimiento, pero solo como un medio, un punto de partida. El objetivo no es explicar a Dios, sino agradecerle, suplicarle, en una palabra: cantarle" (80).

Por eso la describe en otro trabajo diciendo que: "se trata de una teología monástica, que es bíblica, litúrgica y patrística por sus fuentes y su expresión; es práctica por su orientación, es decir una doctrina para la vida” (81), es así que:

"Podemos pensar en un cierto carácter de unidad realizado en dos maneras. En primer lugar, unidad entre las diferentes "fuentes cristianas" que se reducen a tres: la Biblia, la liturgia y la literatura patrística antigua, de las que se han dicho que constituyen el triángulo de base sobre el que se edifica toda la cultura cristiana... realizaban en su enseñanza la síntesis viva de todas las riquezas provenientes de las tres fuentes de base. En segundo lugar, realizaban igualmente la síntesis de todas sus "potencias" o facultades como medios para asimilar todo este conocimiento... Ellos aplicaban todo su ser al dato tradicional, sin que su corazón estuviera reducido al silencio mientras su cabeza estudiaba..." (82).

Su finalidad no era tanto el conocimiento de la verdad como el amor a la verdad, la satisfacción no tanto de la inteligencia como del corazón, no buscaba la

saber y de la demostración. La theologia cristiana se formuló en cuestiones al texto sagrado y poco a poco se fue haciendo más especulativa, con independencia de la Scriptura. El saber cristiano quedó bajo el régimen de la dialéctica, del razonamiento y la demostración lógica. La tercera etapa, ya a comienzos del siglo XIII, contribuyó con un material que ya no era puramente formal sino que concernía el orden mismo de los conceptos y el contenido del pensamiento. El saber cristiano se encontró con una Metafísica, una Antropología y una Ética, y se constituyó bajo el régimen de la Metafísica. Pero si bien en general la escolástica acogió progresivamente la filosofía y la ciencia griega, árabe y judía, se deben distinguir también tendencias diversas en su interior. Hubo una escolástica que quiso continuar, si bien a su modo, en la línea monástica, que acogió completamente a san Agustín, al Pseudo Dionisio y a la herencia filosófica del neoplatonismo, su representante es la corriente agustiniano-franciscana.

(80) “Teología y oración”, p. 74.

(81) Espiritualidad occidental. Testigos, p. 262.

(82) Jean Leclercq, "Lectura, cultura y vida espiritual", en CuadMon 45 (1978), pp. 186-187. 
scientia con sus exigencias de racionalidad, sino la sapientia para llegar así a una vida inmersa escatológicamente en Dios, para obtener un intellectus fidei pleno y perfecto. Por eso no procedía por conclusiones y razones demostrativas, sino que, al situarse ante un punto determinado de los misterios divinos, interrogaba a las fuentes bíblicas, litúrgicas, patrísticas y literarias, ya sean cristianas o no, acerca los demás aspectos buscando una inteligencia espiritual, una contemplación de las cosas divinas en la que la razón tenía como cometidos: elaborar una visión de conjunto y eliminar las falsas interpretaciones.

\section{CUESTIÓN III: LA NOCIÓN DE CIENCIA EN L'AMOUR DES LETTRES ET LE DÉSIR DE DIEU}

El quid del problema epistemológico lo encontramos planteado en el quinto párrafo del capítulo noveno donde leemos:

“... vale más no preguntarse... si la teología de los monjes, fue de carácter científico, si fue una ciencia, o si fue una sabiduría... Además, la ciencia puede definirse por su método -el cual varía según las posibilidades de cada época-, o por su grado de certeza; pero la idea que uno se forma de esta ha evolucionado también... La teología es una disciplina, en la que, partiendo de la revelación y guiada por ella, son interpretadas, elaboradas, y ordenadas en un cuerpo de doctrina, las verdades de la religión cristiana. Basta que se realicen los elementos de esta noción general para que se pueda hablar de teología; ahora bien todos ellos se encuentran en la teología monástica... Se da, verdaderamente, una reflexión sobre los datos de la fe y la búsqueda de una visión de conjunto de esos datos... Queda por determinar si en una época dada se distingue de otra teología en la Iglesia y, en caso afirmativo, en qué medida se distingue" (83).

Nuestro autor trata paradójicamente el problema del status epistemológico de la teología monástica medieval desde las coordenadas metodológicas que le proporcionan dos ciencias: sociología e historia, de las culturas y mentalidades, y partiendo de un concepto moderno-contemporáneo de ciencia, definido por el método utilizado o por el grado de certeza del sujeto, ambos redefinidos por el contexto, y al hacerlo replantea necesariamente la definición y unidad de la teología en general recurriendo a una noción muy genérica de la misma.

Aunque afirma: "Fundamentalmente no hay más que una teología, lo mismo que no hay más que una Iglesia, una fe, una Escritura, una tradición, y un magisterio" (84), sin embargo en su concepción debe haber, o mejor dicho, se debe justificar, el pluralismo teológico, para que la monástica recupere su perdido y merecido lugar.

(83) Cultura y vida cristiana, pp. 232-233.

(84) p. 233. 
Las teologías se diversificarán por poner de relieve algún aspecto del único misterio de salvación o alguno de los componentes de la reflexión cristiana. Si la teología de los claustros se distingue de la teología de las escuelas, no se distinguen en cuanto a lo esencial, en cuanto al método: beber en las fuentes cristianas, el punto de partida y la guía es siempre la luz de la revelación; y apelar al uso de la razón, que clarifica, interpreta, elabora y ordena en un cuerpo de doctrina estas las verdades. En definitiva los dos métodos, monástico -con su preferencia por las autoridades, la experiencia y la gramática- y escolástico -que recurre a lo razón, léase dialéctica y metafísica, de los filósofos-, no son más que dos aspectos complementarios del único método teológico. La diferencia a primera vista podría estar entonces en las mediaciones, los instrumentos y las técnicas, utilizadas. Pero veamos la posición de nuestro autor.

En la teología monástica medieval se utilizaba, como lo demuestra sobradamente el texto que estamos analizando, el método teológico, es decir, se realizaba una reflexión racional sobre los datos de la fe y la búsqueda de una visión de conjunto de esos datos. No era un mero empirismo religioso o descripción anímica, no eran solo consejos práctico-ascéticos o una enseñanza pastoral, no fue exclusivamente literatura o poesía. Era verdadera teología, pero esto lleva a una nueva pregunta: ¿se distingue y en qué medida de la teología escolástica de la misma época? (85). Ya lo expusimos en la cuestión anterior, la clave está en los contextos y las mentalidades, en la cultura y la vida cristiana. En sus propias palabras: "Solo dentro de las grandes unidades culturales que se han sucedido en la vida de la Iglesia, es donde se pueden distinguir corrientes diversas, pero no separarlas... (Porque) a medida que una cultura evoluciona y se enriquece, se diversifica, sin perjuicio de su unidad" (86).

El contexto no solo justifica la distinción, sino que también explica la existencia de una multiplicidad de "teologías monásticas", en una diversidad que les es inherente, "por encima del "fenómeno monástico", y en el corazón mismo de su variedad, se sitúa el "misterio monástico", en su paradójica riqueza" (87). Por eso en una misma época podemos encontrarnos con la teología más "objetiva" de los monjes negros, a la que Leclercq dedicó sus primeras investigaciones (88), y la "subjetiva" de los blancos, a los que consagró sus últimos años (89), y dentro de la primera, la "litúrgica" de Cluny y la "pastoral" de Gorze, para poner solo algunos ejemplos. Pero como "todos sus autores tienen ese carácter común de ser monjes" le fue posible discernir lo que en su teología les es propio y específico (90).

(85) Cfr. Ibidem.

(86) p. 234.

(87) Espiritualidad occidental. Testigos, p. 440.

(88) La spiritualité de Pierre de Celle 1115-1183 (1942); Pierre le Vénérable (1946); Un maître de la vie spirituelle au XII siècle: Juan de Fécamp (1956); Saint Pierre Damien: ermite et homme d'Eglise (1960).

(89) Entre 1957 y 1977 publicó con Charles Hugh Talbot y Henri-Marie Rochais la edición crítica de las obras de san Bernardo en ocho volúmenes, entre 1962 y 1992 los cinco volúmenes del Recueil d'études sur saint Bernard et ses écris, completados por el resumen expositivo seguido de una antología en Saint Bernard et l'esprit cistercien (1966) y una visión psicológica Nouveau visage de S. Bernard. Approches pshycho-historiques (1976).

(90) Cultura y vida cristiana, p. 234. 
La teología es una ciencia. Las ciencias se definen por su método. El método da tanto la coherencia al conocimiento, cuanto el grado de certeza al sujeto. El método varía de acuerdo a los sujetos y sus contextos culturales, y progresa según las posibilidades y los límites de las épocas. Consecuentemente la idea de ciencia va evolucionando también.

Categorías contemporáneas: subjetividad, historicidad, contextos, mentalidades y culturas, son las que entran en juego en el pensamiento de nuestro autor para solucionar la cuestión epistemológica. Como afirma un teólogo español:

"A todo texto escrito precede un lenguaje, a todo lenguaje un uso de la razón, y a toda razón una forma de vida. A la altura del pensamiento en el siglo XXI ya podemos diferenciar esas implantaciones en la realidad de las que brotan una actitud diferente ante la existencia y con ella un pensamiento... Los libros, y las formas equivalentes de textos escritos, tiene detrás de sí esos tres niveles o fases de historia... No hay libro sin palabras, que remiten a un determinado uso de razón, a un universo de sentido y a un horizonte de futuro" (91).

Dom Leclercq era un "espíritu siempre ávido de conocer al hombre que se esconde detrás de los textos" (92).

No podemos dejar de citar, aunque sea extenso, un texto publicado en 1965 en cual nos presenta dos testigos privilegiados de la espiritualidad occidental: Bernardo de Claraval, por la teología monástica, y Tomás de Aquino, por la escolástica:

"Ha habido siempre en la Iglesia espíritus a los que Dios inclinaba a buscar más el conocimiento de la verdad en sí, si podemos expresarnos de esta manera, es decir, un conocimiento objetivo e impersonal de los misterios de Dios... Otros se sienten más arrastrados hacia una teología más subjetiva; estudian los que esos misterios son para ellos, y la relación íntima que tienen con su existencia. A estos pertenece Bernardo. Por eso su teología es inseparable de esa experiencia cristiana de que habla tan frecuentemente. Más tarde, un santo Tomás sabrá disociar la ciencia cristiana de la experiencia religiosa. En san Bernardo ambas van unidas, y no quiere separarlas: toda su ciencia no es más que el análisis de su experiencia. Para santo Tomás es, por decirlo así, la ciencia de la salvación en general; prescinde de lo personal y de lo concreto. Para Bernardo es la ciencia de la salvación tal como se realiza en él y en cada uno de nosotros. Bernardo no llega a lo universal sino por el camino de lo personal y de lo concreto; la historia sagrada que él estudia es su propia historia... Ambos métodos han tenido sus ventajas en la vida de la Iglesia..." (93).

(91) Olegario González de Cardedal, "Filosofía y teología", en Revista de Occidente 258 (2002), pp. 5.7 .

(92) Bernabé Dalmau, op. cit., p. 174. Se le podría aplicar lo que se ha dicho de un "intelectual" del medioevo: “... lo que le apasiona y urge es el método de la indagación más que el objeto investigado, el recorrido teórico del análisis más que su tema particular" (Mariateresa Fumagalli Beonio Brocchieri, El intelectual entre Edad Media y Renacimiento, op. cit., p. 29)

(93) Espiritualidad occidental. Testigos, pp.331-332. 
Es evidente la primacía del sujeto, la praxis, el ethos y el tiempo sobre el objeto, la teoría, el logos y el ser. En el trasfondo se encuentra la noción metafísica del ser como pura relación subsistente, una unidad consistente en dejar de ser permanentemente unidad. El ser es porque se desarrolla y desenvuelve. El tiempo resulta constitutivo de toda la realidad. La verdad es necesariamente histórica. Pero estas son ya cuestiones metafísicas que se resuelven en otro orden.

Su concepto de ciencia evidentemente ya no es el clásico aristotélico, en el que una disciplina se especificaba y ordenaba jerárquicamente por su objeto de investigación, y era este mismo el que determinaba el método que mejor le permitía conseguir lo que se proponía, o sea, su conocimiento coherente, cierto y verdadero por sus causas. Nuestro autor era muy consciente de ello cuando escribía en torno a la primera cuestión epistemológica de la escolástica, "Utrum sacra doctrina sit scientia":

"Tal problemática aparece, sino en el transcurso del siglo XIII... La discusión se convirtió muy pronto, en parte, en una disputa de palabras, a lo que hay que añadir que la noción estrictamente aristotélica de ciencia dejó más tarde de ser aplicable a ciertas ciencias" (94).

\section{CUESTIÓN IV: LA CRITICA NEOESCOLÁSTICA A L'AMOUR DES LETTRES ET LE DÉSIR DE DIEU}

Consideremos ahora brevemente una de las lecturas que la tercera escolástica realizó de L' amour des lettres et le désir de Dieu. El R. P. Luis Ferro, op. en su comentario titulado intencionalmente: “¿Teología monástica y teología escolástica?" escribía:

"Lo que ocurre es que el autor considera en la teología dos aspectos: el primero está basado en la objetividad del conocimiento y el segundo en la función vital del mismo... considera en la teología como en cualquier otra ciencia una doble especificación. Una por parte del objeto, en cuanto este determina el ser y por consiguiente la unidad de la ciencia; otra por parte del sujeto, en cuanto causa eficiente del conocimiento" (95).

Lógicamente hablando no puede aceptar esta doble especificación atendiendo a caracteres metodológicos. No niega que el objeto pueda ser considerado con métodos diversos: método intuitivo y el método deductivo o inductivo, lo que niega es que la teología tenga una determinación genérica por parte de su objeto: Dios; y una determinación específica por parte del método, el modo como el sujeto alcanza la inteligibilidad del objeto. Subjetivo y objetivo tampoco pueden ser considerados como especies dentro de un mismo género.

(94) Cultura y vida cristiana, p. 232.

(95) Luis Ferro, “¿Teología monástica y teología escolástica?”, en Estudios Teológicos y Filosóficos I, I (1959), Notas y comentarios, p. 255. 
La verdad en cuanto producto de la subjetividad, la experiencia y el método que se utiliza es, para el dominico, de un orden completamente distinto al de la objetividad, universalidad y cientificidad. Por eso no es posible probar la disyunción entre la teología monástica y la escolástica atendiendo a los caracteres metodológicos: la vida contemplativa de los monjes (96), la desconfianza por la dialéctica (97), la "sancta simplicitas" (98), la experiencia como fuente de la teología (99), el conocimiento por amor (100), el respeto por lo santo (101), etc.

La tesis de Dom Leclercq es, para el fraile mendicante, que los monjes utilizaron y aún cristianizaron toda la literatura pagana (102), léase gramática y retórica, pero que desconfiaron sistemáticamente del tercer elemento del trivium, la dialéctica de los filósofos, y por ende de la teología con método escolástico. Lo primero es un hecho, por tanto es indiscutible, como lo es también la preferencia de los monjes por lo intuitivo y simbólico, pero no implica el menoscabo de la teología en tanto especulación de la inteligencia y en cuanto que utiliza la dialéctica (103).

El benedictino parece reconocer esto al aceptar la "disputa escolástica" entre Bernardo de Claraval y Pedro Abelardo, aunque aclara que la fuente del ataque monástico no hay que buscarla en las doctrinas de los lógicos, sino en la santidad de vida (104). En Consideraciones monásticas sobre Cristo en la Edad Media reafirma que la teología monástica:

"No excluye el uso de la dialéctica: san Bernardo, Guillermo de Saint- Thierry y otros saben argumentar de manera rigurosa, e incluso sutil. Sin embargo, los problemas de teología especulativa, heredados de la tradición platónica, apenas les preocupan... Pero este espacio reservado a la polémica sigue siendo en ellos secundario: lo que les interesa es el hombre en sus relaciones íntimas con Dios... Esta preocupación explica la importancia que otorgan, más que a los razonamientos abstractos, a la experiencia espiritual" (105).

En síntesis, los monjes serían poetas o literatos, pero no teólogos. La conciliación del amor a las letras con el deseo de Dios es realizada en detrimento del rigor intelectual, de la claridad lógica de los conceptos y de la solidez argumentativa propia de la ciencia teológica. Y Ferro concluye afirmando: "para buscar a Dios siendo hombre hay que buscarlo utilizando la inteligencia en las verdades reveladas" (106).

Evidentemente este predicador no era partidario del exponere reverenter, sino que leyó L' amour des lettres et le désir de Dieu desde las categorías epistemológi-

(96) Cultura y vida cristiana, pp. 234 ss.

(97) pp. 243-251.

(98) pp. $252 \mathrm{~s}$

(99) pp. $259 \mathrm{~s}$

(100) pp. $271 \mathrm{~s}$

(101) pp. 249.276 ss.

(102) pp.152-153.

(103) Cfr. Luis Ferro, op. cit., p. 257.

(104) pp. 256-257.

(105) Consideraciones monásticas sobre Cristo en la Edad Media, p. 169.

(106) Luis Ferro, op.cit., p. 257. 
cas aristotélico-tomistas, las cuales rechazaba explícitamente Leclercq por ser obsoletas, razón por la cual respondió a las cuestiones antes planteadas:

I) negando que los monjes medievales fueran teólogos, porque la teología es especulación dialéctica y metafísica sobre Dios;

II) refutando la distinción metodológica entre monástica y escolástica, porque no puede haber una doble especificación: por el objeto y por el método; y

III) corrigiendo la noción de ciencia, porque esta se determina y especifica por el objeto, aunque este pueda ser abordado con métodos diversos.

Para concluir le cedemos la palabra a Dom Leclercq que en su artículo "Teología monástica" parece responder a la crítica de la escolástica:

"Esta forma de hablar (teología como sabiduría) y la aspiración espiritual que traduce, han reaparecido, con algunas excepciones, en todas las épocas en las que la especulación escolástica, tan legítima y útil cuando se ha limitado a ser una parte y forma de la teología, quería ser la única y, por lo mismo, quería sustituir a la teología tradicional" (107).

Por eso la neoescolástica convierte a la monástica despectivamente en literatura espiritual, poesía piadosa o, a lo sumo, en una mera "anticipación" preescolástica, falseando así las perspectivas históricas y perjudicando la investigación, porque "la objetividad -le gustaba decir- se sitúa a igual distancia de la apologética y de la hipercrítica" (108). Esta metodología conduciría a considerar circularmente a todo período de la teología como la preparación de otro (109). Y cita al canónigo $\mathrm{Ph}$. Delhaye:

"Sin razón y por una falta sorprendente del sentido de la analogía en los que se hacen sus líderes, se ha negado a esta doctrina y a esta investigación el nombre de teología, para reservarlo únicamente al método dialéctico, por otra parte tardío en la Iglesia. El método deductivo no es el único que se impone en el terreno religioso" (110).

Estas dos maneras de hacer teología no se benefician en nada al excluirse y desacreditarse mutuamente, por lo que concluye:

"Hemos de saber apreciar el valor positivo absoluto y definitivo de todo lo que, en contextos históricos y sociológicos diferentes, ha contribuido a la edificación de la Iglesia y de su pensamiento... Además, todo genio escapa a las determinaciones del tiempo, lugar, especialidad, para ser la luz y el alimento de todos" (111).

(107) Jean Leclercq, “Teología monástica”, en Cistercium 125 (1972), p. 30.

(108) Espiritualidad occidental. Testigos, p. 219.

(109) Cfr. Cultura y vida cristiana, p. 232.

(110) Citeaux in den Nederlanden 9 (1959), p. 234, citado en "Teología monástica”, op. cit., p. 35.

(111) Idem., pp. 32 y s. 
Así se manifiesta partidario de la "complementariedad" en la multiplicidad y de la "coexistencia pacífica" entre los diversos modos de pensar la fe, enraizados en las fuentes y en la tradición siempre viva y actual de Iglesia (112), porque: "Una teología "católica", verdaderamente universal, no puede beber en una de esas fuentes (refiriéndose a las teologías) y excluir las otras; hay que beber en todas, y unir sus diferentes aportaciones" (113).

\section{RESUMEN}

Este artículo plantea cuatro cuestiones epistemológicas a propósito de la teología monástica medieval: existencia y significado, distinción de la escolástica, noción de ciencia y crítica neoescolástica, exponiendo reverentemente lo que Dom Jean Leclercq, osb. monje, historiador y teólogo, enseñó especialmente en L'amour des lettres et le désir de Dieu, que es a la vez el título y la conclusión de un hermoso libro publicado hace ya cincuenta años, mostrando la posible "complementariedad" y "coexistencia pacífica" entre modos diversos de hacer teología.

\section{ABSTRACT}

This article outlines four epistemological questions apropos of medieval monastic theology: existence and meaning, the scholastic distinction, the notion of science and neoscholastic criticism, expounding reverently what monk, historian and theologian Dom Jean Leclercq, o.s.b., taught, especially in L'amour des letters et le désir de Dieu, which is at the same time the title and the conclusion of a beautiful book published 50 years ago, showing the possible "complementarity" and "peaceful co-existence" between different modes of doing theology.

(112) Cfr. L'amour des lettres et le désir de Dieu, Avant-propos la $3^{e}$ édition.

(113) Espiritualidad occidental. Testigos, p. 369. 